\title{
Editorial
}

\section{Elective replacement of the aortic root in Marfan's syndrome}

\begin{abstract}
Most patients with full-blown dissection of the ascending aorta in Marfan's syndrome die within days. The few survivors remain at high risk of dying in subsequent weeks. ${ }^{1-2}$

Because a patient with Marfan's syndrome who has acute dissection faces almost certain death, there may be no alternative but emergency surgery with a high operative mortality. Dissection is the cause of sudden death in most patients with Marfan's syndrome ${ }^{45}$ so the logical approach would be to operate electively before dissection occurs. If we were confident that the surgical risks were small we would have little difficulty in making such a recommendation, but in a young, symptom free patient, leading an active life, working full time, and caring for a family we must feel justified in taking even a moderate surgical risk. If there is significant aortic valve regurgitation surgery may be indicated on more established grounds - to relieve symptoms or to preserve deteriorating left ventricular function. This makes the decision easier to make, but in a patient who is entirely symptom free the prospect of aortic root replacement may seem daunting. This is the dilemma we face in deciding when to recommend elective aortic root replacement in symptom free patients with Marfan's syndrome.
\end{abstract}

\section{Surgical decision making}

To make rational decisions about operating to improve prognosis, three pieces of numerical information are required-the prognosis without operation, the risk of the surgery, and the prognosis after the operation has been accomplished. We can attempt to apply these general rules of surgical decision making to asymptomatic Marfan's syndrome.

- Firstly, we need to know the likelihood of aortic dissection (or rupture) in that individual. This requires an ability to identify high risk subsets rather than the general risk for all those with the diagnosis.

- Secondly, we need to know the risk of operation under the prevailing circumstances, refined as far as possible to include patient and surgeon related risks and probabilities of success.

- Finally, we need to know the residual risk, after a successful operation-because replacement of the aortic root does not completely neutralise the hazard of the aortic pathology.

The simple truth is that some of the numerical components required in the decision making process are incomplete, unreliable, or simply not available: but we should use those we have as logically as possible.

\section{Natural history}

We know that life expectancy in Marfan's syndrome is halved ${ }^{45}$ and that aortic dissection is the commonest cause of death. ${ }^{56}$ We must be aware of the tendency for mortality data to be distorted by those presenting with aortic complications and for surgical series to collect the more florid examples of aortic disease ${ }^{7}$ but we need to be in no doubt that the natural history of Marfan's syndrome includes a high risk of sudden and premature death from aortic disease. The only guidance in the literature to help identify the patients most at risk is the aortic root dimension. This can be obtained easily and noninvasively in most patients by transthoracic echocardiography but some, particularly those with pectus excavatum, need transoesophageal studies. ${ }^{89}$ The annulus itself may be a little enlarged but the danger area is in the proximal aorta, at the level of the tops of the aortic commissures. Several aortic root dimensions can be measured depending on the level chosen and the obliquity of section, so we prefer to store the images on tape and review them together, applying consistent measurements if we wish to follow the growth of the aorta over time. A group from Johns Hopkins Hospital have suggested $6 \mathrm{~cm}$ as the threshold at which dissection is sufficiently likely to occur in the foreseeable future to justify planned surgery in the symptom free patient. ${ }^{6}{ }^{10}$ This is in fact a very conservative measurement and we recommend elective surgery if the aortic root expands to $5.5 \mathrm{~cm}$, or sooner (as the group from Johns Hopkins Hospital did in an earlier publication $^{11}$ ) if a series of studies shows progressive expansion. This recommendation is influenced by data from a series of 148 patients studied at St George's Hospital between 1980 and $1990 .{ }^{12}$ In 11 patients dissection occurred when their latest aortic root dimensions averaged $5.1 \mathrm{~cm}(\mathrm{SD} 1.3)$ compared with an average dimension of $3.7 \mathrm{~cm}(1.3)$ in those who remained well (p $<0.005)$, though as always with data of this kind there was considerable overlap.

One of the problems is that some patients present with annuloaortic dilatation and aortic regurgitation without an apparent tendency to lethal dissection. In others dissection occurs while the annulus is small, suggesting to some that the phenomena of dilatation and dissection are unrelated. These opinions seem to be based on individual cases remembered because they appeared to be paradoxical. Our data, as well as those of Gott and colleagues, suggests that dilatation is a warning of the increasing probability of dissection rather than a declaration that the patient has a different (that is non-dissecting) pattern of aortic disease. It is also said that an old healed dissection is often found during planned root replacement. One does find healed intimal splits, appearing almost like stretch marks, but I have searched and not found any evidence that these are the hallmark of a healed "dissection" as we use the term, or that a dissection-that is a propagating separation of the layers of the aortic wall over some considerable length-heals to such a minimal intimal lesion.

From an extensive study of families in the Marfan's Association it appears that there are "dissecting" and "non-dissecting" families, an observation also made by Gott et al..$^{10}$ If a patient with a large aortic root has a parent and siblings who died young not only do we believe that they are at considerable risk but it is also much easier for the family to appreciate the need for an intervention 
and to come to terms with advice to undergo major surgery in an asymptomatic phase of the illness.

\section{Operative risk}

The second piece of numerical information required, if we are to pursue our goal of rational decision making, is the perioperative mortality. In the UK Cardiac Surgery Register the nearest descriptive category, replacement of the ascending aorta, includes 100 to 200 operations per annum, for the ten years between 1980 and 1989, with a relatively small downward trend in mortality from 25 to $20 \% .{ }^{13}$ These data include all ages, all aetiologies, emergencies, and a range of technical expertise, so they may be an overestimate of the mortality for a planned operation in a selected case, but they also include less radical operations, in more surgically amenable aortic tissue, in which case they might underestimate the true risk. Other than reminding ourselves that we are discussing relatively dangerous surgery, it is difficult to apply these data specifically to elective root replacement in Marfan's syndrome. Although as a general rule it is useful to know registry data rather than self selected results from the published reports of surgery, in this instance, where we are discussing planned surgery to safeguard the future of young symptom free patients, centralisation of expertise is perhaps appropriate and therefore we should look to the results achieved by experts. The Johns Hopkins series with no deaths in 44 elective cases (95\% confidence interval $0 \%-8 \%$ ) indicates the level of technical competence that can be achieved. ${ }^{10}$ All my patients who had elective replacement of the aortic root have survived but I am mindful of the width of the confidence intervals around a zero numerator in a small series. ${ }^{14}$

The operation is essentially that first performed by Bentall. ${ }^{15}$ The root must be replaced down to the annulus (with the exclusion of the sinuses of Valsalva) and with reanastomosis of the coronary arteries. The distal anastomosis is made just before the brachiocephalic artery. Surgeons vary in how they anastomose the coronary arteries, whether they use commercially produced or selffashioned composite grafts, and whether they resect all the aorta or use it to wrap the graft. ${ }^{16-18}$ But the operation as performed by Ross, ${ }^{16}$ Gott and colleagues, ${ }^{10}$ and as currently used at St George's Hospital, has changed only in detail from Bentall and De Bono's original description. Most agree that a mechanical valve should be used because though we and others ${ }^{19}$ have successfully reoperated 8-10 years later to change a tissue valve within a conduit, this is a situation best avoided. The hazard of anticoagulation has to be accepted and if there is subsequent aortic rupture, survival will probably be determined by more fundamental considerations than the INR (international normalised ratio) at the time.

\section{Postoperative course}

Finally we need to know whether the survival prospects of the patient with a new aortic valve and ascending aorta are significantly improved. Taken together there are six series which contribute 444 patients. $^{71016172021}$ The criteria of diagnosis of Marfan's syndrome for some of the series are less strict than for others but they show broad agreement in long-term results, with five year survival of about $80 \%$ and ten year survival of $60 \%$. It is clear that expectation of life is still well short of normal for groups of patients in their thirties. The causes of death are not always known but include further aortic events, mitral valve disease, and other cardiac problems.

\section{Marfan's syndrome and pregnancy}

The young woman with Marfan's syndrome wishing to have children or already pregnant presents a particular problem. The risk of having an affected baby is $50 \%$. If after genetic counselling a woman wishes to have children, she should probably have them sooner rather than later. It is difficult to estimate the true risk of the pregnancy to the mother's aorta. Women in the Marfan's Association have had children and passed the gene from one generation to another but one only meets the women who survive. The perception from reviewing case reports in cardiac journals is that the risk of rupture during pregnancy is high but there one reads of tragedies and heroic salvage. Our experience places the risk well into double figures but probably better than even odds. It seems reasonable that the aortic root should be measured at first presentation and its size monitored throughout pregnancy by transthoracic echocardiography. This non-invasive, harmless investigation may give warning. Treatment with $\beta$ blockers can be continued during pregnancy, and delivery, near term, should be elective. Experience of the tragedy of aortic dissection around term leads me to suggest, admittedly without adequate data, that an anaesthetist's careful control of the blood pressure during caesarean section is safer than a natural labour.

\section{Summary}

We offer elective aortic replacement to those we regard as being at high risk. The aortic root dimension and its rate of increase are the best predictors we have. We regard 5.5 $\mathrm{cm}$ as the probable upper limit and we are inclined to advocate surgery at an earlier stage in high risk families and in women planning pregnancy. These operations are planned for a calculated gain in life expectancy and it would be reasonable for there to be a degree of centralisation of referral and development of surgical expertise. We use $\beta$-blockade for life, both before and after surgery, in all patients with Marfan's syndrome with aortic root enlargement. The data on which these recommendations are based are incomplete and we can only hope that with an increasing number of carefully documented cases we will refine them and improve upon them in the future.

The concept of a "forme fruste" or a "Marfanoid aorta" in the absence of the syndrome is highly questionable so the comments made apply only to patients with Marfan's syndrome-not to other forms of annuloaortic ectasia or other less well characterised forms of aortic root disease.

St George's Hospital,

TOM TREASURE

Blackshaw Road,

London SW17 OQT

1 Hirst AE, Johns VJ, Kime SW. Dissecting aneurysm of the aorta: a review of 505 cases. Medicine 1958;217:279.

2 Anagnostopoulos CE, Prabhakar MJS, Kittle CF. Aortic dissections and aortic aneurysms. Am $\mathcal{f}$ Cardiol 1972;30:263-73.

3 DeSanctis RW, Doroghazi RM, Austen WG, Buckley MJ. Aortic dissection. $N$ Engl f $M$ 1987;317:1060-7.

4 Halpern BL, Char F, Murdoch JL, McKusick. A prospectus on the prevention of aortic rupture in the Marfan Syndrome with data on survivorship without treatment. Hopkins Med $\mathcal{F}$ 1971;129:123-9.

5 Murdoch JL, Walker BA, Halpern BL, Kuzma JW, McKusick. Life expectancy and causes of death in the Marfan syndrome. $N$ Engl $f$ Med 1972;286:804-8.

6 Pyertiz RE, McKusick VA. The Marfan syndrome: diagnosis and management. N Engl f Med 1979;300:772-7.

7 Marsalese DL Mill CC Sterba R, Cosgrove DM, Passalacqu AM, Goormastic M, Kovacs A. Marfan's syndrome: Natural history and long term follow-up of cardiovascular involvement. $\mathcal{F}$ Am Coll Cardiol 1989;14:422-8.

8 Simpson IA, de Belder MA, Treasure T, Camm AJ, Pumphrey CW. Cardiac manifestations of Marfan's syndrome: improved evaluation with transoesophageal echocardiography. Br Heart $\mathcal{f} 1991 ; 66: 74$.

9 Simpson IA, de Belder MA, Treasure T, Camm AJ, Pumphrey CW. Cardiac manifestations of Marfan's syndrome: improved evaluation with transoesophageal echocardiography. Br Heart 7 1993;69:104-8.

10 Gott VL, Pyeritz RE, Magovèn :GJ Jr, Cameron DE, McKusick VA. Surgical treatment of aneurysms of the ascending aorta in the Marfan syndrome: Results of composite giaft repair in 50 patients. $N$ Engl $\mathcal{F}$ Med 1986;314:1070-4. 
11 McDonald GR, Schaff HV, Pyeritz RE, McKusick VA, Gott VL. Surgical management of patients with the Marfan syndrome and dilatation of the ascending aorta. $\mathcal{F}$ Thorac Cardiovasc Surg 1981;81:180-6.

12 Murgatroyd F, Child A, Poloniecki J, Treasure T, Pumphrey CW. Does routine echocardiographic assessment of the aortic root diameter help predict the risk of dissection in the Marfan syndrome? [abstr]. Eur Heart f 1991;12(suppl):410.

13 UK Cardiac Surgical Register.

14 Hanley JA, Lippman-Hand A. If nothing goes wrong is everything alright? Interpreting zero numerators. $¥ A M A$ 1983;249:1743-5.

15 Bentall M, DeBono A. A technique for complete replacement of the ascending aorta. Thorax 1968;23:338-9.

16 Donaldson RM, Ross DN. Composite graft replacement for the treatment of the ascending aorta associated with aortic valve disease. Circulation 1982;66(Suppl I): $116-21$.
17 Cabrol C, Pavie A, Mesnildrey P, Gandjbakhch I, Laughlin L, Bors V, Corcos $T$. Long-term results with total replacement of the ascending Surg 1986;91:17-25.

18 Kouchoukos NT. Composite graft replacement of the ascending aorta and aortic valve with the inclusion wrap and the open techniques. Semin Cardiovasc Surg 1991;3:171-6.

19 Shawkat S, Sarangi PP, Firmin RK. A technique for replacing a prosthetic valve after total aortic root replacement. Br Heart $\mathcal{F}$ 1990;63:260-1.

20 Svensson LG, Crawford ES, Coselli JS, Safi HJ, Hess KR. Impact of cardiovascular operation on survival in the Marfan patient. Circulation
constion cardiovascular operation

21 Pasic M, von Segesser L, Carrel T, Bauer E, Laske A, Turina M. Surgical treatment of cardiovascular complications in the Marfan syndrome: 27 year follow up. (Unpublished). 